17 Running title: Stakeholders' perspectives of elephant welfare University of Salford, The Crescent, Greater Manchester M5 4WT, UK Brackenhurst Campus, Southwell, Nottinghamshire NG25 0QF, UK Framlington Place, Newcastle NE2 4HH, UK

*Contacts for correspondence and requests for reprints: lucy.asher@ncl.ac.uk/lisa.yon@nottingham.ac.uk

\title{
CL Chadwick ${ }^{\dagger}, E$ Williams ${ }^{*}$, L Asher**\# and L Yon ${ }^{* *}$
}

${ }^{\dagger}$ Ecosystems and Environment Research Centre, School of Environment and Life Sciences,

Faculty of Medicine and Health Sciences, School of Veterinary Medicine and Science, University of Nottingham, Sutton Bonington Campus, Loughborough LE12 5RD, UK

$\S$ School of Animal Rural and Environmental Sciences, Nottingham Trent University,

${ }^{*}$ Centre for Behaviour and Evolution, Institute of Neuroscience, Newcastle University,

19 Abstract

20 Recent concerns over the welfare of elephants in UK zoos have implications for their future in captivity, and it is clear that improvements in welfare should be made. Evidence suggests 
that the knowledge of experienced stakeholders is vital to captive animal welfare assessment. However, there have been few attempts to consult with zoo personnel and other stakeholders on the assessment of elephant welfare, and much of their valuable knowledge of routine husbandry has not been captured in the published literature. As part of a research project commissioned by the Department for Environment Food and Rural Affairs, open response focus groups and workshop discussions were conducted with representatives from 15 UK elephant-holding facilities, and other experts in the welfare and behaviour of captive or freeranging elephants. Participants described three broad categories of welfare indicators: behavioural, physical and physiological. Resources perceived to be of importance to elephants included aspects of the physical environment, such as feeding opportunities and appropriate substrate, and aspects of the social environment, including group size and relatedness. The data obtained during this study can be used to develop an elephant welfare assessment strategy, informed by the knowledge and expertise of experienced stakeholders, and for consideration of potential changes to guidelines for managing elephants in captivity. Our approach to capturing the views of those who work closely with captive species could be applied elsewhere, in order to draw upon the extensive knowledge of expert stakeholders and consider ways to improve the welfare of captive animals.

Keywords: animal behaviour, animal welfare, elephant, stakeholder opinion, welfare assessment, zoo

\section{Introduction}

Concerns over the welfare of elephants in UK zoos have implications for their future in captivity (Zoos Forum 2010), and improvements in elephant welfare must be made (Clubb \& 
47 Mason 2002; Clubb et al 2008; Harris et al 2008). For the purposes of this study, animal

welfare is considered to be a concept which encompasses mental and physical health, engagement with the physical or social environment, and the opportunity to exhibit control or choice (Asher et al 2015). The assessment of wild animal welfare in captive contexts can be difficult. There are typically few animals of each species in captivity, and little standardisation in husbandry and housing (Hill \& Broom 2009; Mason 2010). Behavioural observations are central to the assessment of welfare (Dawkins 2004; Veasey 2006; Hill \& Broom 2009; Mason \& Veasey 2010), and some previous studies began laying the groundwork to assess elephant welfare in the UK. Clubb and Mason (2002) carried out an epidemiological assessment which gave an overview of elephant welfare across zoos. They cited behavioural problems, reproductive problems and high mortality rates as indicators of poor welfare, although they did not collect new data or explore the behaviour of individual elephants. Their report subsequently drew criticism and it was suggested that their findings were, in places, based on anecdotal evidence (Rees 2003). Harris and colleagues (2008) analysed behaviour and welfare across 14 British and Irish zoos. Using behaviour (including aggression and stereotypies), health, faecal glucocorticoid metabolites and aspects of the environment (including housing and space allowance) as welfare indicators, overall welfare scores were assigned to individuals. The results revealed welfare concerns, such as a significant correlation between increasing age and poor welfare, but due to restrictions of time and funding, welfare was assessed in a 'snapshot' fashion, based on very brief and limited behavioural observations.

In a recent review of welfare indicators in captive elephants, Williams and colleagues (submitted) identified 37 unique welfare indicators from 30 studies. These included resting behaviour (Laws et al 2007; Koyama et al 2012), social behaviour (Schmid 1995; Stoinski et al 2000); abnormal behaviour (Rees 2009; Hapeslagh et al 2013), cortisol levels (Grand 
et al 2012) and body condition (Wemmer et al 2006). Behavioural indicators were used most frequently to assess welfare; however, some of the studies reviewed were limited by small sample sizes and short duration. In addition, conclusions were often based on only one or two welfare indicators. The authors advocated the systematic validation of welfare indicators, and concluded that a more comprehensive approach to welfare assessment should be developed in consultation with relevant stakeholders.

While previous studies have focused on measuring the current welfare state of elephants, no studies, to date, have collected evidence to make targeted suggestions for the improvement of individual elephant welfare on a routine basis (Williams et al submitted). Furthermore, although evidence indicates that the knowledge and experience of keepers is vital to animal welfare assessment (Meagher 2009; Whitham \& Wielebnowski 2009; Tetley \& O’Hara 2012), there have been few attempts to consult with zoo personnel and other stakeholders on assessing elephant welfare in a systematic manner. This is surprising, given the extensive knowledge of zoo personnel (Harris et al 2008; Gurusamy et al 2014) and the absence of a substantial body of scientific evidence on captive elephant welfare (Gurusamy et al 2014; Asher et al 2015).

Harris and colleagues (2008) consulted 50 elephant experts on welfare issues. Participants were asked to list, in their opinion, the ten most important indicators of good and poor welfare in elephants. Eighty-six percent of 50 respondents listed some aspect of behaviour as one of the ten most important welfare indicators, while $84 \%$ mentioned some aspect of physical health. Similarly, Gurusamy and colleagues (2014) conducted an online survey of stakeholders' opinions of the key welfare issues for captive elephants. Elephant keepers, representatives of animal welfare organisations, scientists, zoo directors and veterinarians completed the survey, in which respondents were asked to consider the relative importance of a pre-determined list of husbandry practices and their desirability for elephant welfare. The 
results revealed 15 key welfare concerns, with enclosure substrate, group size and healthcare

rated as the three most important. Although differences in opinion emerged among

stakeholder groups, the authors advocated the inclusion of diverse stakeholder opinion in the development of welfare standards.

In order to accurately assess and improve captive elephant welfare, there is a need for a holistic approach to welfare assessment, incorporating scientific evidence and expert opinion. With this in mind, the purpose of the current study was to gather stakeholders' opinions on measures of captive elephant welfare, and resources thought to be of importance to elephants. We consulted representatives from elephant-holding facilities, and academics and other experts in the behaviour and welfare of captive and free ranging elephants. Instead of a closed question survey, such as that used by Gurusamy and colleagues (2014), open response focus groups were used to capture stakeholders' experiences and insights. A focus group is 'an informal discussion among selected individuals about specific topics' (Beck et al 1986; p 73). It involves one or more group discussions, in which participants focus on a topic or topics selected by the researcher (Wilkinson 1998), with discussion guided by pre-determined questions. Since participants are encouraged to discuss and debate with one another (Wilkinson 1998), focus groups are particularly useful for exploring participants' knowledge and experiences, and can generate more ideas than one-to-one interviews (Morgan 1996; Wilkinson 1998; Barbour 2008).

Focus groups have been used effectively to gather stakeholders' opinions of animal welfare issues. Skarstad and colleagues (2007) held focus groups with consumers to investigate public perceptions of farm animal welfare. They found that consumers equated good welfare with animals 'living as close to nature as possible' (Skarstad et al 2007; p 78), and a 'caring and personal farmer-animal relationship' (Skarstad et al 2007; p 78). Similarly, Miele and colleagues (2011) consulted with stakeholders to develop a method of assessing farm animal 
welfare. Focus group participants were asked to consider what issues they felt were important when assessing the welfare of production animals. Their responses were used alongside the views of animal scientists to develop a list of welfare measures, and a quantitative scoring system for assessing animal welfare.

This study was conducted as part of a research project commissioned by Defra (WC1081), which was designed to develop and validate a new behavioural welfare assessment tool for elephants, and inform an evidence-based update to current management guidelines for elephants. The larger project involved a critical review of the reliability and validity of indicators of elephant welfare reported in the peer-reviewed literature (Williams et al submitted), consultation with zoo personnel and other stakeholders (reported here), and the development and testing of a new behavioural welfare assessment tool, for use by keepers, to assess and monitor individual elephant welfare (Asher et al 2015). The aims of the current study were:

- To consult and engage with a wide and representative range of stakeholders from across UK elephant-holding facilities;

- To collate information from stakeholders to assist in the development of the new welfare assessment tool, tailored to individual elephants, that can be used to develop targeted action plans to improve elephant welfare; and

- To gather stakeholder opinion on resources of importance to elephants, for consideration of potential changes to UK guidelines for managing elephants (the Secretary of State's Standards of Modern Zoo Practice [Defra 2012] and the British and Irish Association of Zoos and Aquariums Management Guidelines for the Welfare of Elephants [BIAZA 2010]). 


\section{Study design}

Stakeholders were invited to participate in telephone focus groups and a workshop discussion. Focus groups were conducted using teleconferencing technology in order to minimise costs and maximise the number of stakeholders that could participate. A semistructured interview method was utilised. Questions were informed by a systematic literature review (Asher et al 2015; Williams et al submitted) and were kept consistent across all focus groups. Specific, pre-planned prompts were used to stimulate discussion where necessary. A copy of the script used to conduct the focus groups can be found in Appendix 1 (see supplementary material to papers published in Animal Welfare on the UFAW website: http://www.ufaw.org.uk/t-ufaw-journal/supplementary-material). The subsequent workshop with stakeholders was then held to facilitate further discussion and to gather opinions on the relative importance of resources that had been identified during the focus groups.

\section{Participant recruitment and response}

All 17 elephant-holding facilities from the UK and the Republic of Ireland were invited to participate in the study; 15 kindly agreed to take part. Facilities participated in either the focus groups alone $(n=3)$, the workshop alone $(n=3)$, or both $(n=9)$. Fourteen focus groups were held with 25 zoo representatives from 12 facilities (1-4 individuals from each facility). In addition, five further focus group discussions were held with eleven experts on the welfare and behaviour of captive or free-ranging elephants from across the world. These details are summarised in Table 1. All participants signed a consent form which informed them of their rights as voluntary participants. The study and consent process was approved by the University of Nottingham's ethics committee. 


\begin{tabular}{lll}
\hline $\begin{array}{l}\text { Participant } \\
\text { Origin }\end{array}$ & Role of participant & $\begin{array}{l}\text { Number of } \\
\text { participants }\end{array}$ \\
\hline Zoos & Keeper & 14 \\
(UK/Ireland) & Curator/Manager & 8 \\
& Veterinarian & 2 \\
& Zoo-based researcher & 1 \\
\hline $\begin{array}{l}\text { Other } \\
\text { (worldwide) }\end{array}$ & Studies behaviour or welfare, captive or free- & 11 \\
\hline
\end{tabular}

All participants had worked with or studied either Asian (Elephas maximus) or African elephants (Loxodonta africana), or both species. Mean (SEM) time spent by participants working with African elephants was 4.3 (5.0) and ranged from none to 14 years $(\bar{x}=4.3$ years; $\sigma=5.01$ years) and time spent working with Asian elephants was 8.3 (8.19) ranging from none to 31 years. Focus groups were conducted by at least one of the authors (CC, LA, LY) and lasted approximately $60 \mathrm{~min}$.

\section{Focus group and workshop topics}

Focus group discussions were structured around two general themes: measures of elephant welfare, and resources perceived to be of importance to elephants. Questions relating to elephant welfare centred on the use of behaviour to assess the welfare of captive elephants. Participants were encouraged to reflect upon how they would generally assess the welfare of any elephant, rather than the individual elephants currently in their care. Participants were also asked to name specific behavioural indicators of both good and poor welfare in captive elephants. The second set of questions centred on features of the environment that are important to elephants. Participants were asked to describe their ideal elephant exhibit,

191 including indoor and outdoor exhibits, and any environmental enrichment that is beneficial for elephants. 
Following the completion of the focus group discussions, a list of resources important to elephants was compiled, based on the resources identified from focus group discussions, and from a review of existing literature on resources of importance to elephants (Asher et al 2015; Williams et al submitted). A workshop was held at one of the participating zoos, at which there were 27 participants (including 21 representatives from eleven elephant-holding facilities, and six experts in the welfare and behaviour of captive or free-ranging elephants). Working in six groups of four or five individuals (plus a facilitator in each group), participants were asked to rank each of the identified resources on a scale of 1 (not important) to 10 (most essential). In order to capture their immediate reactions, the groups were asked to briefly consider_each resource and agree on its relative importance. Independent facilitators in each group ensured that all participants had the opportunity to contribute equally to the discussions. Where participants could not agree on a ranking, the group did not submit a score for that resource.

\section{Data analysis}

Focus groups were audio-recorded (with participant consent) and transcribed; any information relating to the identity of the participants was removed from the transcripts. Data were analysed using thematic analysis (Braun \& Clarke 2006; Krueger \& Casey 2009), a method for 'identifying, analysing, and reporting patterns (or themes) within data' (Braun \& Clarke 2006; $p$ 79). This involved coding interesting features of the data in a systematic fashion, collating codes into potential themes, and defining, naming and reviewing the themes (Braun \& Clarke 2006). Passages of the transcripts containing comments or discussion on similar themes by participants were highlighted and grouped together (see Devitt et al 2014). As our focus was on welfare outcomes, themes were identified within a framework of relevance to either measures of welfare, or resources of importance to 

was used to assist the data analysis process.

220 Each workshop group's submitted rankings were used to calculate a mean ranking and range

221 for each resource. The resources were then placed in order of relative importance to

222 elephants, as discussed by the workshop participants.

\section{Results}

225 Thematic analysis of the focus group transcripts resulted in identification of six key themes

226 relating to measures of welfare and resources of importance to elephants (Figure 1).

227 Participants described behavioural, physical and physiological measures of welfare, and 228 considered aspects of the physical and social environment, and environmental complexity as important resources. Consideration of the individual was a prominent cross-cutting theme throughout. Participants emphasised the importance of developing welfare measures that are

231 tailored to individual elephants, and cautioned against using a simple 'one size fits all' 232 approach to measuring welfare. 
Figure 1 Key themes relating to measures of elephant welfare and resources of importance to elephants, identified via thematic analysis.

\section{Measures of elephant welfare}

Participants described three broad categories of welfare indicators: behavioural, physical, and physiological (Figure 1). A complete list of welfare indicators identified by participants can be found in Appendix 2 (http://www.ufaw.org.uk/t-ufaw-journal/supplementary-material).

\section{Behavioural indicators of welfare}

Behavioural indicators of welfare included natural behaviours (behaviours that would be observed in wild elephants), abnormal behaviours, and interactions with people. Natural behaviours included feeding, social interaction, exploration, digging, swimming, mud wallowing, object play and scratching or rubbing. The presence of natural behaviours, as opposed to abnormal behaviours, was thought to indicate good welfare, and the absence of natural behaviours indicated poor welfare. Participants specifically mentioned sleep and lying rest as measures of welfare (Table 2). Time spent by elephants sleeping or lying down to 
Table 2 Examples of participants' comments on behavioural indicators of welfare.

\begin{tabular}{ll}
\hline Natural & "Showing natural behaviours that would also be present in wild populations, so for \\
behaviours & example natural kind of foraging behaviours, feeding behaviours with browse, exploring \\
their habitat as they would in the wild."
\end{tabular}

"I think sleeping is quite important, we've now seen that [Elephant Name] at the moment here with us, she's actually sleeping, so lying down comfortably, for between four and six hours a night, so I think that's quite important visually, to see an elephant sleeping and knowing that she actually gets the rest."

Social "I think how the whole herd responds to a situation is really important, and that also gives behaviours you a good indicator of the bonds within the group and if there's a strong bond, that to me is good welfare, because that means you've got an adhesive [sic] herd, which is more natural, so if you actually had a situation where the other elephants are getting distressed if another elephant is in pain or showing signs of illness, that to me is a good response from those other elephants."

Stereotypic "So if you saw an elephant with stereotypic behaviour in one facility, it's not necessarily behaviours to say that that facility is not - has got welfare issues for that elephant. It could be that that elephant came there with that condition and it's very difficult to get them out of it once they've got it."

"We kind of try and understand why they're stereotyping, so we look at where, what time of the day, is there anything that we could put in place to prevent that happening, you know, to keep them busy and stimulated. I mean, if it's because they're anticipating or there's an expectation, if appropriate we can make sure that expectation is fulfilled, or create something else so that they're not waiting on us."

Positive social interactions that were mentioned included affiliative behaviour, play, and

physical proximity to another elephant or elephants. Behavioural synchrony within the group,

"feeding together, spending time together, using enrichment together", was described as an

indicator of good welfare, as well as members of the group supporting one another, or

"banding together" in times of stress. Some participants also commented that the behaviour

of the group as a whole can provide information about the welfare of individuals (Table 2). 
participants that some aggression would be likely to occur within a social group ("you always get family squabbles"), but that excessive or hyper-aggression would be cause for concern.

A particularly interesting behavioural indicator suggested by participants was demeanour. This included body language and other, more qualitative measures of welfare that can be difficult to quantify ("it's something that's quite difficult to describe but I and other members of my team do say they sort of get a feeling sometimes that they do look happy"). Keepers particularly commented that their own knowledge of individual elephants in their care was important when assessing welfare. These comments not only highlighted the role of keepers in welfare assessment, but also the need to tailor welfare assessment to the individual elephant ("the knowledge of experienced keepers is priceless really, because you will know your elephants if you've worked with them for a long time").

Abnormal behaviours that were discussed included stereotypies, coprophagy and self-directed behaviours. Stereotypic behaviours that were mentioned included weaving, swaying, pacing and head-bobbing. Some participants stated that they viewed stereotypic behaviour as an indicator of poor welfare ("an obvious one is we all talk about stereotypical [sic] behaviour, you're going to see that in a stressed elephant"). However, many participants commented that stereotypic behaviours may indicate that an elephant had experienced poor welfare in the past, rather than reflecting an elephant's current welfare state. Indeed, a common theme of the discussions was that stereotypic behaviour, and welfare in general, may be substantially affected by experiences from an elephant's past. Regardless of the origin of stereotypic behaviour, participants also commented on methods used to alleviate or reduce the occurrence of stereotypies (Table 2). Interactions with keepers were also mentioned as behavioural indicators of welfare. Negative interactions with keepers, or an elephant not responding to training or not co-operating with 
keepers, were seen as signs of poor welfare. Conversely, an elephant responding well to training, co-operating and being engaged in training was seen as a sign of good welfare.

\section{Physical indicators of welfare}

The second category of welfare measures identified from the discussions was physical indicators of welfare. These were often mentioned in response to the first focus group question: ‘How would you visually assess elephant welfare?' Poor foot condition, lameness, an unhealthy gait and an inability to lie down and get up were seen as indicators of poor welfare.

Body condition scoring or weight was a commonly mentioned physical indicator of welfare, with obesity in particular being seen as an indicator of poor welfare. However, participants also commented that body condition scoring can be difficult to use and quite subjective, and not appropriate for every elephant: “you do have some elderly elephants that don't particularly fit in to everything on a body scoring chart". This was another instance in which a participant commented that welfare measures should be appropriate to the individual.

\section{Physiological indicators of welfare}

The final category of welfare measures was physiological indicators of welfare. Physiological indicators were not as commonly discussed in the focus groups as behavioural or physical measures of welfare, most likely because the questions focused specifically on visual assessment of elephant welfare. Physiological indicators of welfare included measurement of stress hormones ("if you did faecal glucocortisone [sic] analysis, that may show if there is stress going on there"), and, in African elephants, temporal gland secretion ("we check the temporal glands for secretion, especially at moments of excitement"). Nonetheless, participants did comment on the use of physiological indicators to assess welfare, and the 
benefits of being able to regularly take blood samples from their elephants to monitor physiological changes (“at the moment we're actually taking samples, faeces samples of [Elephant Name], the more aggressive elephant, to see if there's an issue with hormonal or stress levels as well").

\section{Resources of importance to elephants}

Participants discussed three broad themes of resources they considered to be important for welfare: aspects of the physical environment, aspects of the social environment, and choice and environmental complexity (Figure 1). A complete list of resources identified by participants can be found in Appendix 3 (http://www.ufaw.org.uk/t-ufawjournal/supplementary-material). The list of resources and environmental features generated by the focus groups, and from the existing literature, were discussed at the workshop. The workshop discussion resulted in a ranked list of resources of importance to elephants, ordered from 'most essential' (those resources ranked 8,9 or 10) to 'not important' (those ranked 1, 2 or 3). Resources ranked as 'most essential' are presented in this section.

\section{Physical environment}

Physical features of the environment that participants described as important for welfare included feeding opportunities, mud wallows, opportunities for scratching or rubbing, types of substrates provided, and water features.

Many participants emphasised not only the importance of food to elephants ("so much is based around their daily life of feeding"), but also the importance of methods of presenting food to elephants. In particular, feeding from height and providing browse were regarded as methods of feeding that encouraged captive elephants to show natural behaviours (Table 3). Indeed, ten enrichment and feeding resources were ranked as 'most essential' by the 
Table 3 Examples of participants' comments on resources of importance to elephants.

\begin{tabular}{|c|c|}
\hline $\begin{array}{l}\text { Physical } \\
\text { environment }\end{array}$ & $\begin{array}{l}\text { "I think it's important to add as well on varying levels, as well, because historically } \\
\text { again, elephants have been given food on the floor and that in turn can affect the } \\
\text { muscles in the upper part of the trunk because they're not using those muscles to } \\
\text { stretch or reach for food as they would do in the wild for browse on trees." }\end{array}$ \\
\hline & $\begin{array}{l}\text { "In regards to the physical fitness of the animals, it's hard to imagine anything other } \\
\text { than increased fitness if you're moving over hilly terrain or an undulating terrain, } \\
\text { you're going to be using more muscle groups if you're clambering up or down over a } \\
\text { little hillock than you would do if you were just on a flat pad." }\end{array}$ \\
\hline
\end{tabular}

"You know - behaviour chains, for instance, an elephant gets wet, an elephant throws sand, an elephant goes and rubs. Perfect example of a behaviour chain that you don't need really much to do with an elephant, you just need to get the beast wet, she'll throw sand if she has it, and she'll rub if she has something to rub against."

Social "I think that specifying minimum group size could actually be counterproductive in environment terms of welfare where you might get a collection that's striving to meet the absolute guidelines and then forcing four elephants that hate each other to live together and then compromising them in terms of space, social dynamics and everything like that and actually making all four of those elephants miserable."

"We're trying to move forward and create the family groups with the different age ranges, but we still have a lot of older elephants still in captivity that need to, sort of, have the correct environment for their needs, and maybe some of them wouldn't do well in a big collection of a variety of ages but they do very well in their pairs."

Space and "I've seen a problem in some collections with choice between substrates, and that's complexity not been a good thing because they've chosen to sleep on a concrete floor that's actually not good for them, rather than on sand, so yeah it doesn't always work."

"You can never give them the space, an animal like this in the captive environment, so whether it is 500 acres or 1000 acres or only 50 acres, to the animal itself it won't make a big difference if it's not challenging, the habitat should be challenging so they can interact with different items, different substrates, they have to make choices."

"I think in an ideal world you would have multiple enclosures that were joined together and that could be accessed at different times, ideally under the control of the elephants, but you would also have other species using those enclosures so that it would be more complex. You know, olfactory smells and they could modify the environment, so the next time they went into it, it would be a bit different." 
Table 4 Enrichment and feeding resources ranked as most essential (8 or higher).

\begin{tabular}{lccc}
\hline Resource & $\begin{array}{c}\text { Number of groups } \\
\text { providing a ranking }\end{array}$ & $\begin{array}{c}\text { Mean } \\
\text { ranking }\end{array}$ & Range \\
\hline Browse provided daily & 6 & 10.0 & 10 \\
Food provided in such a manner which provides & 6 & 10.0 & $8-10$ \\
$\quad$ intellectual stimulation (e.g. puzzle feeders, hidden & & & \\
$\quad$ treats, etc.) & 6 & 10.0 & 10 \\
Trees/branches & 6 & 10.0 & 10 \\
Variety of food and methods of feeding & 6 & 9.7 & $9-10$ \\
Food distributed throughout the day & 6 & 9.7 & $9-10$ \\
Some food placed up high so that elephants must & & & \\
$\quad$ stretch to reach it & 6 & 9.5 & $8-10$ \\
Scatter feed or similar that encourages exercise & 4 & 8.8 & $8-10$ \\
Regular provision of novel enrichment & 5 & 8.6 & $5-10$ \\
Toys (e.g. tyres) & 6 & 8.2 & $5-10$ \\
Large logs & & & \\
\hline
\end{tabular}

${ }^{\text {a }}$ Only groups that reached agreement provided rankings.

Provision of appropriate substrate was also thought to be important for welfare. Whilst it was

generally acknowledged that concrete can be beneficial in some areas of elephant enclosures

(for example in areas used for veterinary treatment), participants advocated the use of the substrate for activities such as sleeping or dustbathing.

Some participants also commented on the benefits of providing a variety of substrates to add complexity to the captive environment. In addition, variation in terrain was described as an important feature for welfare, with undulations in terrain allowing elephants the opportunity for physical exercise and providing visual barriers ("we're lucky we have big, large, grass paddocks with a lot of undulations where they can get away from each other, dominant ones and lower ranking ones"). Participants also indicated the importance of mud wallows, water features and scratching or rubbing posts in elephant exhibits. These features were often identified as tools for allowing elephants to express natural behaviours within the captive environment, providing the opportunity for social interaction and physical exercise (Table 3). 
371 Participants commented on observing social interactions, such as play, around mud wallows

372

373 and pools, as well as highlighting the physical benefits of providing deep water in which elephants could swim ("you can actually see that they've exerted themselves and you can see their muscle tone and their condition from the benefits of having pools"). Some participants also commented on the different requirements of Asian and African elephants ("I think Asian elephants tend to like water a lot, so pools tend to get used pretty regularly, you know, they like clean water... but Africans aren't quite the same, you know, Africans might go in clean water but they'd probably prefer to wallow in mud').

\section{Choice and environmental complexity}

During discussions of the physical environment, participants stated that access to resources over a 24 -h period was important for welfare. Ideas for achieving this included providing access to feeding opportunities throughout the day ("I think elephants like to have access to food 24 hours a day so they can choose when they want to feed"), and providing the same resources in indoor enclosures as are available in outdoor enclosures. Participants felt that elephants are often provided many more resources in their outdoor enclosures than indoors ("we don't put the same things inside as we put outside"). Some participants commented that timed feeders were in use at their facility, to allow elephants to feed overnight in the absence of keepers. However, it was also acknowledged that timed feeders should be used with caution, in order to avoid interrupting natural sleeping patterns (“... what they were finding is that the elephants were asleep but as soon as the winches came down with hay they were waking them up").

It was clear from the discussions that the complexity of an enclosure and the resources within it were thought vital (Table 5). Allowing elephants control over their environment and providing them opportunities to choose and make decisions were also thought to be important 
Workshop participants generally felt that giving elephants the option to choose whether to be indoors or out was a good idea, "providing that it was safe for the elephants". Space and complexity were also identified as features of the environment that are important for welfare enclosures were preferable to smaller enclosures ("I think probably about every elephant should be increased.

Table 5 Aspects of the physical environment ranked as most essential (8 or higher).

\begin{tabular}{|c|c|c|c|}
\hline Resource & $\begin{array}{l}\text { Number of groups } \\
\text { providing a ranking }\end{array}$ & $\begin{array}{c}\text { Mean } \\
\text { ranking }\end{array}$ & Range \\
\hline Not chained for long periods (e.g. overnight) & 6 & 10.0 & 10 \\
\hline $\begin{array}{l}\text { Outdoor space allowance to meet current minimum } \\
\text { requirements }\left(500 \mathrm{~m}^{2} \text { per elephant }\right)\end{array}$ & 4 & 10.0 & 10 \\
\hline Complex environments & 6 & 9.8 & $9-10$ \\
\hline Natural light indoors & 6 & 9.8 & $9-10$ \\
\hline $\begin{array}{l}\text { Places to hide from other individuals (i.e. visual } \\
\text { barriers, different areas) }\end{array}$ & 5 & 9.6 & $9-10$ \\
\hline Furniture which enables scratching/rubbing & 6 & 9.5 & $8-10$ \\
\hline $\begin{array}{l}\text { More than one entrance/exit between } \\
\text { houses/paddocks }\end{array}$ & 6 & 9.5 & $7-10$ \\
\hline $\begin{array}{l}\text { Water in the form of a deep pool with a shallow } \\
\text { entrance }\end{array}$ & 6 & 9.0 & $7-10$ \\
\hline Variety of substrates & 6 & 8.8 & $1-10$ \\
\hline Furniture which encourages stretching/climbing & 6 & 8.7 & $6-10$ \\
\hline Good artificial lighting & 6 & 8.7 & $5-10$ \\
\hline Free access indoors/outdoors $24 / 7$ in warmer months & 5 & 8.6 & \\
\hline Free access indoors/outdoors $24 / 7$ year round & 6 & 8.5 & $4-10$ \\
\hline Variety of terrain (e.g. mounds) & 3 & 8.3 & $7-9$ \\
\hline $\begin{array}{l}\text { Indoor space allowance to meet current minimum } \\
\text { requirements }\left(50 \mathrm{~m}^{2} \text { per elephant }\right)\end{array}$ & 5 & 8.2 & $1-10$ \\
\hline $\begin{array}{l}\text { Activities not human led (no or few scheduled } \\
\text { events) }\end{array}$ & 5 & 8.0 & $4-10$ \\
\hline $\begin{array}{l}\text { Places to hide from public (e.g. visual barriers, } \\
\text { different areas) }\end{array}$ & 6 & 8.0 & $3-10$ \\
\hline
\end{tabular}

\footnotetext{
a Only groups that reached agreement provided rankings.
} 
410 When describing their ideal elephant exhibit, some participants told us that they would like to

411 provide live trees or woodland for captive elephants, or experiment with mixed species

412 exhibits to provide additional complexity. Ideas for mixed species exhibits included antelopes

413 such as blackbuck (Antilope cervicapra), giraffes (Giraffa camelopardalis), and even birds or

414 primates.

415

416

\section{Social environment}

417 Features of the social environment that were considered to influence welfare included group

418 size, relatedness, the composition of the group and compatibility between individuals. Ten aspects of the social environment were ranked as 'most essential' by the workshop participants (Table 6).

Table 6 Aspects of the social environment ranked as most essential (8 or higher).

\begin{tabular}{lccc}
\hline Resource & $\begin{array}{c}\text { Number of groups } \\
\text { providing a ranking }\end{array}$ & $\begin{array}{c}\text { Mean } \\
\text { ranking }\end{array}$ & Range \\
\hline Calves stay in maternal group & 5 & 10.0 & 10 \\
$\begin{array}{l}\text { Bulls with females and young } \\
\text { Auditory and visual access to the whole herd at }\end{array}$ & 5 & 9.2 & $7-10$ \\
$\quad$ night & 6 & 9.0 & $4-10$ \\
$\begin{array}{l}\text { Compatible group (affiliative behaviour shown } \\
\quad \text { little aggression) }\end{array}$ & 6 & 9.0 & $7-10$ \\
$\begin{array}{l}\text { Cows and young animals not lone housed } \\
\text { Herd with a wide range of ages }\end{array}$ & 6 & 9.0 & $7-10$ \\
$\begin{array}{l}\text { Physical access to the whole herd at night } \\
\text { Auditory and visual access to some of the herd at }\end{array} \quad$ night & 6 & 8.0 & $7-10$ \\
$\begin{array}{l}\text { Bull lone housed with auditory, visual or olfactory } \\
\quad \text { communication with other elephants }\end{array}$ & 5 & 8.8 & $4-10$ \\
Mixed sex herd & 5 & 8.6 & $4-10$ \\
\hline
\end{tabular}

a Only groups that reached agreement provided rankings.

425 Some participants believed that the size of a social group was important for welfare. Larger 
427 allow for greater variety in group composition ("the bigger your herd is, the more chance you 428 have that elephants get on"). Distinctions were made between the requirements of Asian and African elephants ("comparing them to what might be natural, African group sizes might be bigger and Asian group sizes might be smaller"). However, other participants felt that the compatibility of a social group was more important than the number of elephants ("I would strongly agree that it's not a case of numbers. Numbers don't make elephants happy. I think it's their relationships with each other that would make them contented"). Indeed, some participants highlighted the danger of a recommended group size, which might encourage facilities to house incompatible elephants together to reach the target number, but compromise welfare as a result (Table 3 ).

Whilst there was inconsistency over the ideal size of a group, all participants emphasised the importance of relatedness among group members (Table 6). A multigenerational family group was seen as the ideal social group type for good welfare, mirroring the social groups that occur in wild populations. Welfare benefits of housing elephants in family groups included the opportunity for natural social interaction, close social bonds between individuals, and opportunities for appropriate learning and development, especially in young elephants. However, it was also acknowledged that the current captive population contains unrelated, non-breeding females for whom housing in a family group would not be possible. In these cases, participants felt that compatibility among group members was important for welfare (Table 3), emphasising further the importance of considering individual differences.

\section{Discussion}

The knowledge of experienced stakeholders is considered to be vital in the assessment of captive animal welfare and the development of welfare standards (Meagher 2009; Whitham 
opinions of elephant welfare. In the present study, consultations were held with a wide and representative range of stakeholders from across UK elephant-holding facilities and beyond, and potential measures of elephant welfare and features of the environment which are thought to be of importance to elephants were identified.

Focus group participants identified behavioural, physical and physiological indicators that could be used to assess elephant welfare. This is in agreement with the results of the survey conducted by Harris and colleagues (2008), in which the majority of respondents listed aspects of behaviour and physical health as important welfare indicators. Participants in the focus groups also mentioned some of the welfare factors identified by Gurusamy and colleagues (2014), including enclosure substrate, group size, interactions with keepers, enclosure size and access to wallows. The list of potential welfare measures generated during the focus group discussions (Appendix 2; http://www.ufaw.org.uk/t-ufawjournal/supplementary-material) is also broadly in agreement with the findings of Williams and colleagues (submitted), and recent studies conducted in zoos in North America (Greco et al 2016; Holdgate et al 2016; Meehan et al 2016; Morfeld et al 2016). This may be because these common welfare indicators are well established and frequently discussed by elephant keepers and other stakeholders. However, the qualitative, open response approach and semi-structured interview method employed in the current study allowed participants to make novel suggestions which go beyond the current evidence base, and enabled the collection of more detailed stakeholder opinion on a wide range of elephant welfare issues. In keeping with the findings of Williams and colleagues (submitted), behavioural indicators of welfare were most commonly discussed by stakeholders. However, there were behavioural measures identified in the present study that were not documented in the reviewed literature. For example, keepers, in particular, discussed interactions with people, and demeanour, as two additional potential measures of welfare. Qualitative Behavioural Assessment measures 
animal welfare using descriptors of the animals' affective state (Wemelsfelder 2007). QBA has been validated in other species (eg cattle [Bos Taurus]: Stockman et al 2011; pigs [Sus scrofa domesticus]: Rutherford et al 2012; and sheep [Ovis aries]: Phythian et al 2013). Thus, there may also be merit in applying these methods to captive elephants.

Stakeholders were of the opinion that the expression of natural, species-typical behaviours that would be observed in wild populations indicated good welfare, and that the captive environment should contain resources which enable and encourage elephants to express those behaviours. Particular attention was paid to social behaviour and group composition in both the focus groups and the workshop. This is in agreement with the survey conducted by Gurusamy and colleagues (2014), in which respondents ranked group composition as one of the three most important factors affecting elephant welfare, and with a large body of evidence linking appropriate social group housing with improved welfare in other species (De Rouck et al 2005; Morgan \& Tromborg 2007; Price \& Stoinski 2007).

Although few published studies have used social behaviour as an indicator of elephant welfare (Asher et al 2015; Williams et al submitted), participants in our study recognised the importance of replicating in captivity the social groups that have been observed in wild elephants (Moss \& Poole 1983; Sukumar 1994). There was strong support among stakeholders for multi-generational family groups, comprising a wide range of ages, and for housing social groups together day and night. These comments are echoed in the results of Meehan and colleagues' (2016) recent study of housing and social environments of elephants in US zoos, in which individuals that had the opportunity to interact with juveniles spent, on average, $65.68 \%$ of their time with them. Furthermore, Greco and colleagues (2016) found that aspects of the social environment, including the proportion of time spent with juveniles and the proportion of time spent alone, predicted rates of stereotypic behaviour. In our study, relatedness and the maintenance of family groups were seen as important factors for 
improving welfare. Where this is not possible, participants felt that compatibility among group members should be considered. This was also reflected in the workshop, as relatedness and compatibility were ranked 'most essential'. In addition, participants in both the focus group and workshop discussions felt that setting minimum group sizes may be counterproductive, as welfare may be compromised if incompatible individuals are housed together in order to meet the minimum requirement. Indeed, negative effects of inappropriate or incompatible social groups on animal welfare have been documented, including chronic stress and social tension (Wielebnowski et al 2002; Morgan \& Tromborg 2007; Davis et al 2009).

Choice and complexity were also thought to be important aspects of the captive environment. Focus group participants were of the opinion that, while enclosures should be as large as possible, they should also be challenging, no matter the size. This was reflected in the workshop results, as participants ranked resources offering choice and complexity as 'most essential', and in agreement with respondents to the survey carried out by Gurusamy and colleagues (2014), who ranked 'enrichment' among the top five factors affecting elephant welfare. Participants in both the focus groups and workshop advocated complex environments with a variety of substrates and terrain, free access between indoor and outdoor enclosures, a deep pool, and places where elephants can hide or get away from conspecifics should they choose to do so. This underscores the desire to give elephants as much choice and complexity as possible, which has been identified as an important component of animal welfare (Broom 1991). Emerging evidence indicates the relevance of choice and environmental complexity to elephant welfare. Greco and colleagues (2016) found that the ability to choose between indoor and outdoor enclosures was associated with reduced risk of stereotypic behaviour, whilst Brown and colleagues (2016) reported a link between diverse environmental enrichment programmes and reduced risk of reproductive problems. 
527 Our data highlight the challenges of assessing elephant welfare, as stakeholders emphasised 528 the importance of accounting for differences among individuals, as well as the past histories 529 of these long-lived animals. The UK captive population consists of individuals with diverse 530 origins and backgrounds, including wild-born and captive-born elephants, and individuals 531 originating from circuses or logging camps (Harris et al 2008). Reflecting this, consideration of the individual was a prominent cross-cutting theme throughout the discussions; many participants felt that a 'one size fits all' approach to welfare assessment would be inappropriate. For example, they felt that stereotypic behaviour may not be indicative of an elephant's welfare state under its current environmental conditions. This is also in agreement with the published literature; whilst several studies have adopted stereotypic behaviour as an indicator of welfare in captive elephants (eg Laws et al 2007; Rees 2009; Koyama et al 2012), it is recognised that stereotypies should not be used as the sole indicator of welfare (Mason \& Latham 2004). Stakeholders highlighted the importance of a tailored, holistic method of welfare assessment, which makes use of a suite of indicators, as there is a great deal of individual variation among these long-lived animals. Indeed, Meehan and colleagues (2016) found no significant associations between zoo-level variables (eg herd size and exhibit size) and elephant welfare, but did find significant associations between individual-level variables (eg measures of time spent in a social group) and welfare. Methods of assessing elephant welfare should therefore take into account differences among individual animals. There is a growing body of evidence linking individual differences with animal welfare, and

547 several authors advocate the assessment of welfare from the perspective of the individual, rather than the species or taxon (Hill \& Broom 2009; Whitham \& Wielebnowski 2009; Watters \& Powell 2012). Research by King, Weiss and colleagues (Weiss et al 2002, 2006; King \& Landau 2003; Gartner \& Weiss 2013) has provided evidence that welfare is related to 551 personality in felids and great apes, and studies have begun to explore this link in elephants 
552 (Grand et al 2012; Horback et al 2013; Yasui et al 2013). Given that behavioural

553 observations are central to the assessment of welfare (Dawkins 2004; Veasey 2006; Hill \&

554 Broom 2009; Mason \& Veasey 2010), and keepers are well placed to observe individuals'

555 behaviour, welfare assessments should also incorporate the knowledge and expertise of

556 keepers.

557 In advocating the use of expert opinion in welfare assessments, we recognise that opinion

558 alone should not determine welfare measures, or inform husbandry guidelines. Rather,

559 stakeholder expertise should be considered alongside scientific evidence to develop a holistic

560 approach to welfare assessment. Our results identified potential welfare measures of which

561 there is currently little discussion in the published literature; these should be investigated

562 further for reliability and validity before inclusion in any assessment of elephant welfare.

563

564 Animal welfare implications

565 In the assessment and improvement of captive animal welfare, there is great value in

566 considering input from experienced stakeholders. Our approach to capturing the views of

567 expert stakeholders could be applied elsewhere, in order to draw upon the extensive

568 knowledge of those who work closely with elephants, and other species, and consider ways to

569 improve the welfare of captive animals. Animal welfare scientists should therefore be

570 encouraged to identify and work with relevant stakeholders. We demonstrate how this can be

571 successfully achieved via semi-structured focus groups or interviews. For the purposes of our

572 study, expert stakeholders included zoo keepers, curators, veterinarians and researchers, but

573 in other situations and for other species, this could include farmers, veterinary nurses, kennel

574 or cattery staff and laboratory technicians, for example. This method of consulting with

575 relevant stakeholder groups will ensure that their valuable knowledge is captured and

576 analysed in a rigorous, systematic manner. Our results identified the need for a tailored 

approach to assessing elephant welfare, taking into account the differences among individual animals. When used alongside evidence from the literature, expert opinion can inform husbandry guidelines, the development of welfare assessment tools tailored to individuals, and targeted action plans for improving animal welfare.

\section{Acknowledgements}

We are grateful to Defra for commissioning the research (Developing Behavioural Indicators, as part of a Wider Set of Indicators, to Assess the Welfare of Elephants in Zoos: WC1081), and to members of the Project Steering Group, peer reviewers and Special Advisory Board for their support and guidance. Particular thanks to the facilitators of the workshop: Oliver Burman, Ros Clubb, Matthew Hartley, John Eddison and Samantha Bremner-Harrison. We would also like to thank Moira Harris for sharing the details of her earlier study. The stakeholder focus groups and workshop were invaluable in contributing to our understanding of the practical assessment of elephant welfare and resources of importance to elephants in captivity. We are extremely grateful to all that took part and thank them for their contributions. LY's ORCID is \#0000-0002-9765-3192.

\section{References}

Asher L, Williams E and Yon L 2015 Developing behavioural indicators, as part of a wider set of indicators, to assess the welfare of elephants in UK zoos. Defra WC1081. Defra: Bristol, UK. http://sciencesearch.defra.gov.uk/Document.aspx?Document=12816_Elephantwelfarereport WC1081.pdf

Barbour R 2008 Doing Focus Groups. Sage: London, UK 
601

602

603

604

605

606

607

608

609

610

611

612

613

614

615

616

617

618

619

620

621

622

623

624

Beck L, Trombetta W and Share S 1986 Using focus group sessions before decisions are made. North Carolina Medical Journal 47: 73-74

Braun V and Clarke V 2006 Using thematic analysis in psychology. Qualitative Research in Psychology 3: 77-101

British and Irish Association of Zoos and Aquariums (BIAZA) 2010 Management Guidelines for the Welfare of Zoo Animals: Elephants, Third Edition. BIAZA: London, UK Broom DM 1991 Animal welfare: concepts and measurement. Journal of Animal Science 69: $4167-4175$

\section{Brown JL, Paris S, Prado-Oviedo NA, Meehan CL, Hogan JN, Morfeld K and}

Carlstead, K 2016 Reproductive health assessment of female elephants in North American zoos and association of husbandry practices with reproductive dysfunction in African elephants (Loxodonta africana). PLoS ONE 11: e0145673. doi:10.1371/journal.pone.0145673

Clubb R and Mason GJ 2002 A Review of the Welfare of Zoo Elephants in Europe. RSPCA: Horsham, UK

Clubb R, Rowcliffe M, Lee P, Mar KU, Moss C and Mason GJ 2008 Compromised survivorship in zoo elephants. Science 322: 1649

Davis N, Schaffner CM and Wehnelt S 2009 Patterns of injury in zoo-housed spider monkeys: a problem with males? Applied Animal Behaviour Science 116: 250-259

Dawkins MS 2004 Using behaviour to assess animal welfare. Animal Welfare 13: S3-S7

Department for Environment, Food and Rural Affairs (Defra) 2012 Secretary of State's Standards of Modern Zoo Practice. Defra: Bristol, UK

De Rouck M, Kitchener AC, Law G and Nelissen M 2005 A comparative study of the influence of social housing conditions on the behaviour of captive tigers (Panthera tigris). Animal Welfare 14: 229-238 
Devitt C, Kelly P, Blake M, Hanlon A and More SJ 2014 Dilemmas experienced by government veterinarians when responding to farm animal welfare incidents in Ireland. Veterinary Record Open 1: e0000003

Gartner MC and Weiss A 2013 Scottish wildcat (Felis silvestris grampia) personality and subjective well-being: implications for captive management. Applied Animal Behaviour Science 147: 261-267

\section{Grand AP, Kuhar CW, Leighty KA, Bettinger TL and Laudenslager ML 2012 Using} personality ratings and cortisol to characterize individual differences in African elephants (Loxodonta africana). Applied Animal Behaviour Science 142: 69-75

\section{Greco BJ, Meehan, CL, Hogan, JN, Leighty, KA, Mellen, J, Mason, GJ and Mench JA} 2016 The days and nights of zoo elephants: using epidemiology to better understand stereotypic behaviour of African elephants (Loxodonta africana) and Asian elephants (Elephas maximus) in North American zoos. PLoS ONE 11: e0144276. doi:10.1371/journal.pone.0144276

Gurusamy V, Tribe A and Philips CJC 2014 Identification of major welfare issues for captive elephant husbandry by stakeholders. Animal Welfare 23: 11-24

Harris M, Sherwin, C and Harris S 2008 The Welfare, Housing and Husbandry of Elephants in UK Zoos. Defra: Bristol, UK

Haspeslagh M, Stevens J, De Groot E, Dewulf J, Kalmar I and Moons C 2013 A survey of foot problems, stereotypic behaviour and floor type in Asian elephants (Elephas maximus) in European zoos. Animal Welfare 22: 437-443

Hill SP and Broom DM 2009 Measuring zoo animal welfare: theory and practice. Zoo Biology 28: 531-544.

Holdgate MR, Meehan CL, Hogan JN, Miller LJ, Rushen J, de Passillé AM, Soltis, J, Andrews J and Shepherdson DJ 2016 Recumbence behaviour in zoo elephants: 
650 determination of patterns and frequency of recumbent rest and associated environmental and

651

652

653

654

655

656

657

658

659

660

661

662

663

664

665

666

667

668

669

670

671

672 social factors. PLoS ONE 11: e0153301. doi:10.1371/journal.pone.0153301

Horback KM, Miller LJ and Kuczaj II SA 2013 Personality assessment in African elephants (Loxodonta africana): comparing the temporal stability of ethological coding versus trait rating. Applied Animal Behaviour Science 149: 55-62

King JE and Landau VI 2003 Can chimpanzee (Pan troglodytes) happiness be estimated by human raters? Journal of Research in Personality 37: 1-15

Koyama N, Ueno Y, Eguchi Y, Uetake K and Tanaka T 2012 Effects of daily

management changes on behavioural patterns of a solitary female African elephant

(Loxodonta africana) in a zoo. Animal Science Journal 83: 562-570

Krueger RA and Casey MA 2009 Focus Groups: A Practical Guide for Applied Research, Fourth Edition. Sage: London, UK

Laws N, Ganswindt A, Heistermann M, Harris M, Harris S and Sherwin C 2007 A case study: faecal corticosteroid and behaviour as indicators of welfare during relocation of an Asian elephant. Journal of Applied Animal Welfare Science 10: 349-358

Mason GJ 2010 Species differences in responses to captivity: stress, welfare and the comparative method. Trends in Ecology and Evolution 25: 713-721

Mason GJ and Latham NR 2004 Can't stop, won't stop: is stereotypy a reliable animal welfare indicator? Animal Welfare 13: S57-69

Mason GJ and Veasey JS 2010 How should the psychological well-being of zoo elephants be objectively investigated? Zoo Biology 29: 237-255

Meagher RK 2009 Observer ratings: validity and value as a tool for animal welfare research. Applied Animal Behaviour Science 119: 1-14 
673 Meehan CL, Hogan JN, Bonaparte-Saller MK and Mench JA 2016 Housing and social

674

675

676

677

678

679

680

681

682

683

684

685

686

687

688

689

690

691

692

693

694

695

696

697

environments of African (Loxodonta africana) and Asian (Elephas maximus) elephants in

North American zoos. PLoS ONE 11: e0146703. doi:10.1371/journal.pone.0146703

Miele M, Veissier I, Evans A and Botreau R 2011 Animal welfare: establishing a dialogue between science and society. Animal Welfare 20: 103-117

Morfeld KA, Meehan CL, Hogan JN and Brown JL 2016 Assessment of body condition in African (Loxodonta africana) and Asian (Elephas maximus) elephants in North American zoos and management practices associated with high body condition scores. PLoS ONE 11: e0155146. doi:10.1371/journal.pone.0155146

Morgan DL 1996 Focus Groups. Annual Review of Sociology 22: 129-152

Morgan KN and Tromborg CT 2007 Sources of stress in captivity. Applied Animal Behaviour Science 102: 262-302

Moss CJ and Poole J 1983 Relationships and social structure in African elephants. In: Hinde RA (ed) Primate Social Relationships: An Integrated Approach. Blackwell Science: Oxford, UK

Phythian C, Michalopolou E, Duncan J and Wemelsfelder F 2013 Inter-observer reliability of Qualitative Behavioural Assessments of sheep. Applied Animal Behaviour Science 144: 73-79

Price EE and Stoinski TS 2007 Group size: determinants in the wild and implications for the captive housing of wild mammals in zoos. Applied Animal Behaviour Science 103: 255264

Rees PA 2003 RSPCA elephant welfare recommendations would compromise zoo breeding programmes. International Zoo News 50: 86-90

Rees PA 2009 Activity budgets and the relationship between feeding and stereotypic behaviours in Asian elephants (Elephas maximus) in a zoo. Zoo Biology 28: 79-97 
Behavioural Assessment of emotionality in pigs. Applied Animal Behaviour Science 139:

700

701

702

703

704

705

706

707

708

709

710

711

712

713

714

715

716

717

718

719

720

721

722 218-224

Schmid J 1995 Keeping circus elephants temporarily in paddocks - the effects on their behaviour. Animal Welfare 4: 87-101

Skarstad G, Terragni L and Torjusen H 2007 Animal welfare according to Norwegian consumers and producers: definitions and implications. International Journal of Sociology of Food and Agriculture 15: 74-90

\section{Stockman CA, Collins T, Barnes AL, Miller D, Wickham SL, Beatty DT, Blache D,} Wemelsfelder F and Flemming PA 2011 Qualitative behavioural Assessment and quantitative physiological measurement of cattle naïve and habituated to road transport. Animal Production Science 51: 240-249

Stoinski TS, Daniel E and Maple TL 2000 A preliminary study of the behavioral effects of feeding enrichment on African elephants. Zoo Biology 19: 485-493

Sukumar R 1994 Elephant Days and Nights: Ten Years with the Indian Elephant. Oxford University Press: New York, USA

Tetley CL and O'Hara SJ 2012 Keeper ratings of animal personality as a tool for improving the breeding, management and welfare of zoo mammals. Animal Welfare 21: 463-476 Veasey J 2006 Concepts in the care and welfare of captive elephants. International Zoo Yearbook 40: 63-79

Watters JV and Powell DM 2012 Measuring animal personality for use in population management in zoos: suggested methods and rationale. Zoo Biology 31: 1-12

Weiss A, King JE and Enns RM 2002 Subjective well-being is heritable and genetically correlated with dominance in chimpanzees (Pan troglodytes). Journal of Personality and Social Psychology 83: 1141-1149 

5

Weiss A, King JE and Perkins L 2006 Personality and subjective well-being in orang-utans (Pongo pygmaeus and Pongo abelii). Journal of Personality and Social Psychology 90: 501511

Wemelsfelder F 2007 How animals communicate quality of life: the qualitative assessment of animal behaviour. Animal Welfare 16: 25-31

\section{Wemmer C, Krishnamurthy V, Shrestha S, Hayek LA, Thant M and Nanjappa KA} 2006 Assessment of body condition in Asian elephants (Elephas maximus). Zoo Biology 25: $187-200$

Whitham JC and Wielebnowski N 2009 Animal-based welfare monitoring: using keeper ratings as an assessment tool. Zoo Biology 28: 545-560

Wielebnowski NC, Ziegler K, Wildt DE, Lukas J and Brown JL 2002 Impact of social management on reproductive, adrenal and behavioural activity in the cheetah (Acinonyx jubatus). Animal Conservation 5: 291-301

Wilkinson S 1998 Focus group methodology: a review. International Journal of Social Research Methodology 1: 181-203

Williams E, Chadwick CL, Asher L and Yon L A review of current indicators of welfare in captive elephants (Loxodonta africana and Elephas maximus). Animal Welfare, submitted Yasui S, Konno A, Tanaka M, Idani G, Ludwig A, Lieckfeldt D and Inoue-Murayama M 2013 Personality assessment and its association with genetic factors in captive Asian and African elephants. Zoo Biology 32: 70-78

Zoos Forum 2010 Elephants in UK zoos: Zoos Forum review of issues in elephant husbandry in UK zoos in the light of the report by Harris et al (2008). Defra: Bristol, UK 